\title{
THE SARCOPLASMIC RETICULUM
}

\author{
Its Recent History and Present Status
}

\author{
KEITH R. PORTER, Ph.D. \\ From The Rockefeller Institute, New York
}

The contents of this volume, and most especially the modern morphological observations on the sarcoplasmic reticulum, place in strong relief the neglect that was accorded this component of the sarcoplasm in the 30 to 40 years preceding its recent rediscovery. From the time of publication of Veratti's paper, as D. S. Smith points out in his historical survey (54), various related or unrelated cytological discoveries served to submerge the earlier observations on the sarcoplasmic reticulurn and finally to divert attention almost completely from them. The trophospongium hypothesis of Holmgren, which attracted considerable attention in the first decade of the century, interpreted the sarcoplasmic reticulum as the image of slender extensions of extracellular trophocytes having, supposedly, nutritive functions. Students of the Golgi component found compelling reasons to homologize the system with the Golgi apparatus. And finally, the very existence of the delicate lacework of silver-stained strands that Veratti had depicted in his figures came to be doubted by almost everyone. Reviews on muscle, appearing during the 1940's and early 1950's, neglect the structure entirely. One can readily agree with Bennett (6) in his comment that "it is astonishing that a struc. ture once described as accurately and as beautifully as the reticulum was by Veratti (1902) should have so quickly become almcst lost to man's knowledge". It was from this position of neglect that "man's knowledge" of the sarcoplasmic reticulum was rescued by electron microscopy. As attested by this volume, the study of the system is now back to a level of interest fittingly proportioned to Veratti's early work.

The first paper of recent times which can be said to have identified the sarcoplasmic reticulum in electron micrographs was published in 1953 (7).
The techniques for electron microscopy were then crude and the evidence somewhat short of convincing, but the report adequately made the point that within the sarcoplasm between the myofibrils and beneath the sarcolemma, there is a reticular structure, distributed in repeating patterns related to the sarcomeres of the myofibrils. The unit of structure was observed to be tubular or vesicular and reminiscent of the endoplasmic reticulum (or ER) then being recognized as a common component of other cell types $(33,37,40)$. Connections, apparently comprised of elements of the sarcoplasmic reticulum, were observed to run from the marginal fibrils of the fiber to the sarcolemma at the level of the $\mathrm{Z}$ line. These and other features of this component of the sarcoplasm convinced the observers that they were seeing the electron microscope image of the cross-fiber reticulum of Cajal (1890 (10)), Retzius (1890 (45)), Veratti (1902 (57)), and Heidenhain (1911 (19)) among others. These initial observations by electron microscopy introduced a period of recognition for the sarcoplasmic reticulum (or SR), and a number of investigators of muscle fine structure began to note the same or similar components in electron micrographs of striated muscle from various sources. Ruska (1954 (50)) observed it in several skeletal muscles of the mouse and Weinstein (1954 (59)) in cardiac muscle cells of various vertebrates. Edwards and Ruska (1955 (15)) called attention to its presence in leg muscles of two different insects, but noted its apparent absence from flight muscles. Bennett (1955 (3)) provided some of the best illustrations up to that time of the system in mouse skeletal muscle, and Porter $(1954,1956(38,39))$ reported it in micrographs of muscle fibers from the caudal myotomes of a larval amphibian.

These early observations were soon supple- 
mented by increasingly convincing and detailed images--products of greatly improved preparation techniques, and it was in the following period of 2 or 3 years that most of the major structural features of the reticulum were described $(1,16,27,30,42)$. Thus there emerged a picture of the component as a lacework of tubules and vesicles within the sarcoplasm between the myofibrils. These elements comprising the structure vary in size from 50 to 100 $\mathrm{m} \mu$; they are limited by simple membranes, ca. 5 $\mathrm{m} \mu$ thick, and show no internal structure or content. The membranes are without attached particles and hence appear smooth, but evidence of differentiation is not totally absent because small circular areas of low density, essentially pores, have been seen in the membranes of one form at least, exactly opposite the $M$ line of the adjacent sarcomere (42). In these respects for the most part, the muscle fiber component described as the sarcoplasmic reticulum has the characteristics of the endoplasmic reticulum of other cell types.

It was evident from the observations of this period that each type of muscle fiber contains a somewhat different expression of this component. In some fibers the lacework of tubules is more prominent or more extensively developed than in others, and other differences were evident in the organization of the tubules and vesicles. What was most significant here was the demonstration that the pattern of their arrangement repeats in phase with each sarcomere of the adjacent myofibril. This relationship served, in a general way, to relate the structure to the major functional activity of muscle cells and also to identify the system with the crossfiber, silver-stained reticulum described by Veratti in a wide variety of muscles $(57,58)$.

Among the several remarkable features of the SR there is one of special interest that appears as a differentiation within the limits of the I band. At this level it is common to find in longitudinal sections profiles of three vesicular units. The outer two of this 3-unit group are continuous with the reticular apparatus of the adjacent sarcomeres and appear as foot processes pushed against the intermediary vesicles which never show morphological continuity with the other two. This local differentiation has been called a triad (42). The early observations on it left many uncertainties about the details of its structure and significance-uncertainties which, to some extent at least, have since been cleared up. Such three-part structures were first reported in amphibian muscle by Porter (39), Porter and Pal- ade (42), and by Andersson-Cedergren (2), in cardiac muscle by Porter and Palade (42) and by Lindner (27); and in mammalian skeletal muscle of several kinds by Edwards et al. (16), and Porter and Palade (42). There is ample reason to believe, as well, that pairs of "double membranes," or tubules, as noted in lizard skeletal muscle by Robertson (48), represent the triads of this muscle. Subsequent studies including those reported here have greatly extended and improved on these initial observations.

An interesting and probably functionally significant feature of these triads is their distribution relative to the bands of the myofibril. In the tail muscles of Amblystoma larvae, e.g. where the I band is short and the contraction rate relatively slow, the triads are located opposite the $Z$ line and there is consequently only one triad per I band. The same seems also to be true of cardiac muscle. In other skeletal muscles and also insect muscles of the synchronous type, the triadic units are distributed 2 per I band (and sarcomere) and these are located more or less opposite the A-I junction. This arrangement obviously introduces another repeating division in the reticulum: that which fills in between the triads and lies opposite the $\mathrm{I}$ band and $\mathrm{Z}$ line. The fine structure of this is difficult to decipher and of the few attempts that have been made an excellent example is found in the paper by Fawcett and Revel in this present volume (17). They conclude that in the swim-bladder muscle the complex of tubular structures in this I band reticulum represents an interdigitation of the separate sarcomere systems and is not continuous across the $\mathrm{Z}$ line. It follows from this that in the muscle they studied, each sarcomere division of the reticulum is divided into three parts by the two triads.

Whether at a few places the reticulum is continuous along the long axis of the muscle fiber is still in doubt although Veratti's illustrations would suggest that it is. At this point we find it interesting to note that the "transverse reticula" observed by Veratti in his silver preparations (and corresponding to the triads of the electron microscopic images) also varied in number from muscle to muscle. In some cases there was one opposite the $Z$ line; in other muscles he depicted one opposite each A-I junction and in a few instances three appeared-one opposite the $\mathrm{Z}$ line and one opposite each A-I junction. This variation puzzled Veratti and since he was suspicious of the reliability of his metallic 
impregnation methods he proposed that where the last arrangement of these transverse reticula did not appear the impregnation had failed (58). From all we now know, his results were better than he realized.

\section{The Triad}

The investigations of recent years, including those reported in this supplement, have given more attention to the character and significance of the transversely oriented parts of the system and most especially to the triad. The reasons are several. This part of the reticulum is morphologically unique, and, as pointed out just above, is distributed in precise register with respect to certain bands of the sarcomeres. Again improvements in preparatory techniques and microscopy have provided improved images. Then also interest is focused here because this part of the system in its transverse continuity and relation to the $I$ band is most favorably disposed to play a role in the intracellular conduction of impulses from the sarcolemma transversely into the interior of the fiber which in vertebrate muscles is frequently a distance of 50 to 100 microns. Indeed, the experiments of Huxley and Taylor $(25,26)$ (referred to again below) with microelectrode stimulation seem certainly to involve the triad in this function. What then is the nature of this structure?

The earliest reports, as noted above, directed attention chiefly to the existence of a differentiation of the sarcoplasmic reticulum consisting of three parts localized in register with either the $Z$ line or the A-I junction of the adjacent fibrils (42). The structure has since been described in greater detail and is well illustrated in the paper by Fawcett and Revel (17) in this volume. It has been pointed out that dimensions of spaces between the intermediary vesicles and the two lateral vesicles of the triad are very constant at about $15 \mathrm{~m} \mu$ and that the membranes limiting the smaller intermediary vesicle and the surfaces of the large lateral vesicles facing it are thicker and seem to possess greater density than other membranes of the SR. Continuity of this triadic structure or any part of it across the fiber has not been observed. Only morphological differences were recognized between the central and lateral elements of the triad until Bergman (8) noted, in observations on postmortem changes in frog striated muscle, that the transverse structures opposite the $\mathrm{Z}$ and $\mathrm{M}$ lines survived postmor- tem destruction and glycerol extraction longer than the longitudinally oriented elements of the reticulum.

A recent study by Andersson-Cedergren goes much further in its analysis of the triad (2). On the basis of excellent morphological evidence the author concludes that the intermediary vesicle of the triad should be regarded as a structure distinct and separate from the SR, and refers to it as the transverse or $T$ system. It is observed in the same report that the elements of the $T$ system (the central components of the triads) are highly convoluted tubules which extend over long distances across the fiber. At the periphery of the fiber they are contiguous with the plasma membrane, and it is proposed that the system "represents a component which might conduct the stimulus from the plasma membrane to the interior of the fiber." This is the first paper that makes a bold and clear-cut distinction, morphologically and functionally, between the central and lateral elements of the triad, and assigns to the central element of the triad alone the role of transverse impulse conduction.

A key question in this interpretation, which remained unanswered, was concerned with the existence of some continuity between this component and the plasma membrane. The literature provides abundant suggestive evidence that such exists, and even in the earliest studies on fragments of muscle, before thin sections were available, one finds images of ridges on the inner surface of the sarcolemma which coincide with the $Z$ line of the fibrils (12). Nearly all observers agree that some close association exists, but direct continuity had not been observed except in cardiac muscle. Here, in heart specimens from the dog (Lindner (27)) and the sheep (Simpson and Oertelis (52)), the investigators discovered invaginations of the plasma membrane which extended into the fiber to depths of at least one or two myofibrils and achieved a morphological association with other vesicular components of the sarcoplasm in triads or dyads (41). ${ }^{1}$

This question of continuity is discussed also in the preceding papers in this supplement. Fawcett and Revel (17) observe that the intermediary element of the triad is probably a continuous tubule but find no evidence of continuity with the sarcolemma. Perhaps, however, the observations

${ }^{1}$ Edwards and Challice have described extensive infoldings of the plasma membrane in muscle cells of the cockroach heart (14). 
of Smith are of greatest interest in this regard (55). The salient point he makes is that the extensive infoldings of the plasma membrane of insect (Tenebrio) flight muscles, introduced to the interior of the fiber along with the tracheoles of the respiratory system, bring the membrane into intimate contact with all the fibrils though in this case not at a preferred level with respect to the sarcomere. In this relationship to the fibril then, these infoldings are similar to the intermediary vesicles in the vertebrate fibers. Similarly also, these tubular infoldings associate with vesicular elements in the sarcoplasm, not to form triads, it is true, but clearly dyads. It is therefore reasonable to conclude that these infoldings are structurally homologous with the intermediary vesicle of the triad. Continuity with the external plasma membrane can be traced morphologically, but even if this were not so, their three-layered, or unit membrane structure (Robertson (49)), would identify these deep infoldings with the membrane limiting the fiber and distinguish them from other sarcoplasmic membranes which appear as single lines only (55). We find it reasonable to assume that waves of depolarization spreading out from myoneural junctions on the surface of the fiber would follow these infoldings. In the case of these Tenebrio fibers, certainly, the sarcoplasmic reticulum could not function in internal conduction because it is not a continuous system; and so by default, if for no other reason, the role falls to the plasma membrane tubules.

It is to be noted that this propensity of the plasma membrane to associate closely with myofibrils is demonstrated as well in the observations of Peachey on amphioxus muscle (35). Here the sheet-like form of the fiber brings the limiting membrane almost into contact with all the fibrils. The result is effectively the same as in Tenebrio. It is noted that when in amphioxus this device is used there is no evidence of dyad or triad structure, though there appears to be a thin scattering of vesicular units, possibly part of the sarcoplasmic reticulum, between the plasma membrane and the fibrillar substance of the muscle.

From this review of the available information we would propose that the sarcoplasmic reticulum of Veratti (the cross-fiber reticulum of Cajal) consists of two distinct parts: one related to, and possibly derived from, the plasma membrane part of the sarcolemma (see Mauro and Adams, this volume, for definition (29)), and the other the muscle cell equivalent of the endoplasmic reticu- lum. It is true that, in vertebrate skeletal muscles, evidence that the intermediary component of the triads is related to the plasma membrane is meager; in cardiac muscle it is better $(27,52)$. There are, however, observations that the central element in skeletal muscle is different and possibly related to the plasma membrane. For instance, the membrane limiting this intermediary vesicle has been reported as thicker and more dense than other membranes of the reticulum $(39,42)$, and of late, descriptions of it as three-layered in cardiac muscle like the plasma membrane have been published $(27,52)$. If then there is a relationship with the plasma membrane it is odd, yet perhaps explainable, why connections have not been more frequently encountered. We would suggest that continuity may be intermittent. It is conceivable also that connections may exist only over a small area or expanse of the cell surface, easily missed in thin sections. Then, too, the assumed connection may be extraordinarily sensitive to the disturbance of fixation. It is, indeed, reasonable to suggest that the development of a discontinuity is part of the stimulation process and it is probably impossible to fix a muscle without stimulating it. Therefore, what is seen in these subsarcolemmal connections between intermediary vesicle and plasma membrane-the populations of apparently unconnected vesicles--may be a product of a variety of conditions, not to mention AnderssonCedergren's observation that the tubular elements are highly convoluted (2).

Continuity of the $T$ or intermediary system across the fiber or over substantial depths of the fiber has been reported as probable but not really established as a fact of observation. When studied with care and great patience, the evidence is good (2), but here again, a number of features of morphology or function might confuse the observer and make his task difficult. The passage of an excitatory impulse could momentarily disrupt the continuity which may normally exist in the fiber at rest. Fixation may be imperfect. Also, one should keep in mind that the $T$ system at any one sarcomere level may be a many branched system of invaginations. It could invade the fiber at several points on the circumference and by branching reach every fibril within a marginal sector. Continuity in such a system would be extraordinarily difficult to trace with thin sections.

That the rest of the sarcoplasmic reticulum, apart from the $T$ system, represents the ER of the muscle cell has been generally assumed and is sup- 
ported by evidence of connections between it and the nuclear envelope (30), by the morphology and distribution of the component parts, and by the character of the limiting membrane. It, unlike the plasma membrane, is only about $50 \mathrm{~A}$ thick and does not appear to show the three-layered structure of Robertson's unit membrane.

\section{Functions}

Considerations of the function of this system in the muscle have, for lack of information, been largely speculative. Retzius (1881) has been repeatedly quoted (3-6) as having suggested that the system serves to conduct the excitatory impulse in to the interior of the fiber. Since, however, Retzius was not actually viewing the sarcoplasmic reticulum in $188 \mathrm{I}$ and interpreted what he did see as a continuation of the extracellular nerve net (44), it may be inappropriate to give so much attention to his suggestion. Perhaps the comment made by Veratti (in this volume (58)) with regard to the speculation of Retzius (among others) on the function of the reticulum is as appropriate now as when made. He observes that such ideas "however ingenious, have not been documented with sufficiently precise and certain anatomical data to be unconditionally accepted."

Fortunately, observations and information have accumulated since Veratti's time and provide a firmer basis for speculation. Hence there is some excuse for examining current ideas and interpretations.

To review in detail the background and early development of the conduction hypothesis relative to the sarcoplasmic reticulum would be to repeat in large part what can be found in other papers in this volume and also what has appeared in a number of recent reviews $(6,23)$. It will suffice therefore to summarize only the major bases of current speculation.

As is well known the action potential assumed to be important in the contraction of muscle fibers, is measured at the surface, yet the myofibrils at the center of the fiber (50 or more microns from the surface) contract simultaneously with those at the periphery adjacent to the sarcolemma. The mechanism for coupling the excitation and contraction has not been defined. A. V. Hill has pointed out that diffusion rates would be too slow to carry a stimulating substance from the surface to the central fibrils and that some other mechanism must be involved $(20,21)$. The paradoxical behavior of the small, yet slowly contracting smooth fibers and the large, quickly responding striated fibers emphasizes the phenomenal behavior of the latter type and suggests that different mechanisms must exist in the two cases for transmitting the excitation across the fibers (36): diffusion would be rapid enough in the smooth fiber, but not in the striated. When observations of recent times confirmed the existence of the sarcoplasmic reticulum and pointed out that the patterns in it are related to the sarcomeric structure of the myofibrils, the first thought of the functionally oriented biologist was that here was a morphological system capable of carrying the excitation into the fiber's interior $(3,16,42,51)$. This hypothesis became especially popular after Huxley and Taylor $(25,26)$ and Huxley and Straub (24) demonstrated in their now famous experiments with microelectrodes that myofibrillar responses as deep as $10 \mu$ within the fiber can be elicited by depolarizing the fiber membrane at points which coincide with the location of the triads in the sarcoplasmic system already described (22). Thus was established the concept that some element of the triad is functional in this transverse transmission of the excitatory impulse. Naturally then the recent observations on the fine structure of this element become very important, and for this reason we have reviewed the available morphological information. This in essence supports the conclusion that the central element of the triad is different from the lateral vesicles (2). This difference is variously expressed, but most significantly in its limiting membrane which is usually thicker (39) and may be three-layered like the plasma membrane of the fiber $(27,52)$. In a few instances continuity of the central element with the plasma membrane is documented with convincing evidence $(52,55$, and 56); in other instances intermittent continuity is suggested (42). So the postulate made by Huxley and Taylor that the triadic structure conducts the excitation transversely in the fiber may be narrowed down to apply to the central unit alone. Obviously the hypothesis is only weakly supported as yet, but is certainly worth further investigation.

What then is the function of the rest of the system; i.e., complex of cisternae extending between the intermediary vesicles and in the light of present knowledge most properly referred to as the sarcoplasmic reticulum? This has been interpreted with justification as homologous with the endoplasmic reticulum in other cells $(16,42)$. 
Presumably it may perform in the muscle cell some of the same functions it performs elsewherefunctions of metabolite sequestration and transport $(33,40)$. Fawcett and Revel argue from their observations reported here that the system, in the toadfish muscle they studied, may "take part in the synthesis of energy-rich compounds" (17). But, for none of these suggestions is there any strong evidence in the case of muscle fibers.

One approach to the question, used successfully in studies of the ER in other cells, is to take the system out of the cell and examine its composition and activity for clues to its in situ performance. An attempt at such an isolation is herewith reported by Muscatello et al. and has the important virtue of giving good attention to the electron microscopic identification of the component isolated (31). The results of these workers and those of other independent groups $(13,23,32)$ make it clear that the sarcoplasmic reticulum is the major "particulate" component of a fraction of muscle first studied by Marsh (28). This fraction or some factor in it, Marsh found, has the capacity to inhibit the syneresis of myofibril preparations in the presence of ATP. This so-called relaxing factor therefore inhibits the ATPase activity of myofibrils, but is itself inhibited in the presence of $\mathrm{Ca}^{++}$ion. What makes the story doubly interesting is that the "microsomes" from muscle (fragments of the SR + the $T$ system) have an extraordinary capacity to bind $\mathrm{Ca}$ in the presence of ATP (13). Thus the SR would seem not only to produce the relaxing substance, but to have, within some part at least, the capacity to take up unbound or freely exchangeable $\mathrm{Ca}$ and so maintain conditions favorable for the action of the relaxing factor. Actually Ebashi (13) claims that the Ca binding alone, in that it mimics the action of EDTA (ethylenediaminetetraacetate), is the mechanism of relaxation. But Parker and Gergely (34) state that removal of labile $\mathrm{Ca}$ is not in itself enough to induce relaxation. In any case the important role of $\mathrm{Ca}$ and its exchanges in contraction are reaffirmed (11). Thus far we have little or no evidence to indicate whether different components of the SR fraction do different things, except for some preliminary observations by Revel (47) which show that under certain conditions the membranes in the triad increase greatly in density when the fiber is exposed to $\mathrm{Ca}^{++}$ion during fixation, and so may have an affinity for calcium.
With these various functions assigned, it is tempting to speculate on the sequence of events involved in excitation and contraction, but obviously the information is too meager to make a serious attempt to construct the complete story. Probably, a signal is received at the individual $\mathrm{Z}$ band or A-I junction by way of the intermediary vesicle, or $T$ system. This sets in motion a series of events which may include the release of $\mathrm{Ca}$ in the vicinity of the triad, the activation of the myofibril-ATP mechanism, the uptake of $\mathrm{Ca}$ by the elements of the reticulum, and the release of a relaxing factor which inhibits the ATPase action of the myofibrils.

It is of some interest in this connection to compare various types of muscle with respect to the quantity and complexity of the SR and associated $T$ systems. This becomes meaningful only if one assumes, as morphologists generally do, that hypertrophy of structure indicates a proportional hypertrophy in function. From such comparative studies it is discovered that muscles that contract at extraordinarily high rates of frequency, e.g. the toadfish swim-bladder (Fawcett and Revel (17)), cricothyroid muscle of the bat (Revel (46)), the synchronous flight muscle of the dragonfly (Smith (56)), and the extrinsic eye muscles of Fundulus (Reger (43)) are all richly supplied with this component. Cardiac muscle in general, and turtle heart in particular (17) are notably deficient. It would seem that in instances where a muscle is designed to return to the relaxed state in a few milliseconds (53), the development of the $\mathrm{SR}$ is pronounced. On the other hand, in cases where the muscle is stretched by some external force or relaxes only slowly, the development of the SR is far less prominent. The flight muscles of certain insects, referred to as asynchronous (or fibrillar), are a notable exception to the above correlation but this can be explained on the basis of observations that these muscles relax and contract in an oscillating fashion and are stretched, after contraction, by the thoracic cage and opposing muscles (Boettiger (9) and others). There may in this instance be no relaxation in the usual sense, and there is no synchronous relation between the contractions and the nerve impulses received by the muscle.

Thus we would suggest that the sarcoplasmic reticulum, or the endoplasmic reticulum of the muscle cell, plays an active role in the return of 
the fiber to the relaxed state. Whether this action depends on the production of a relaxing factoror the uptake of $\mathrm{Ca}$ or both-is impossible to say. The SR, as noted by Veratti and many observers since, shows a patterned structure which is distorted in contraction. Possibly the reticulum has some elastic properties or, in an inherent tendency to maintain a set pattern, exerts an influence tending to solate (or relax by $\mathrm{Ca}$ uptake) the surrounding sarcoplasmic matrix (fibrillar components included) and return the muscle cell to its relaxed length.

\section{REFERENCES}

1. Andersson, E., The tubular system in the striated muscle cell, in Proceedings of the Stockholm Conference on Electron Microscopy, (F. S. Sjöstrand and J. Rhodin, editors), New York, Academic Press, Inc., 1957.

2. ANDERSSON-GEDERGReN, E., Ultrastructure of motor end-plate and sarcoplasmic components of mouse skeletal muscle fiber, $J$. Ultrastruct. Research, 1959, suppl. 1.

3. BenNetT, H. S., Modern concepts of structure of striated muscle, Am. J. Physic. Med., 1955, 34, 46.

4. BenNETt, H. S., The sarcoplasmic reticulum of stiped muscle, J. Biophysic. and Biochem. Cytol., 1956, 2, No. 4, suppl., 171.

5. Bennetr, H. S., Structure of muscle cells, Rev. Mod. Physics, 1959, 31, 394.

6. Bennett, H. S., The structure of striated muscle as seen by the electron microscope, in Structure and Function of Muscle, (G. Bourne, editor), New York, Academic Press, Inc., 1960, 1, 137

7. Bennett, H. S., and Porter, K. R., An electron microscope study of sectioned breast muscle of the domestic fowl, Am. J. Anat., 1953, 93, 6r.

8. Bergman, R. A., An experimental study of the non-fibrillar components in frog striated muscle, Bull. Johns Hopkins Hosp., 1958, 103, 267.

9. Boetriger, E. G., Recent Advances in Invertebrate Physiology, (B. T. Scheer, editor), 1957, University of Oregon Press, Eugene, Oregon.

10. Cajal, R. S., Coloration par la methode de Golgi des terminaisons des trachees et des nerfs dans les muscles des ailes des insectes, $Z$. wissensch. Mikr., 1890, 7, 332.

11. Csapo, A. Studies on excitation-contraction coupling, Ann. Nere York Acad. Sc., 1959, 81, 453.

12. Draper, M. H., and Hodge, A. J., Australian J. Exp. Biol. and Med. Sc., 1949, 27, 465.

13. Eвashi, S., Calcium binding activity of vesicular relaxing factor, $J$. Biochem., 1961, in press.
In its present status then the sarcoplasmic reticulum becomes an accepted component of striated muscle fine structure. Its morphological relation to the myofibril suggests a functional involvement in contraction and belief in the validity of this assumption is greatly strengthened by the activities it shows in isolation from the cell. Research on muscle physiology and biochemistry is entering a new phase of activity in which much attention will no doubt be given to the component of muscle fibers which Veratti described just 60 years ago.

14. Edwards, G. A., and Challice C., E., The ultrastructure of the heart of the cockroach, Blattella germanica, Ann. Entomol. Soc. America, 1960, $53,369$.

15. Edwards, G. A., and Ruska, H., The function and metabolism of certain muscles in relation to their structure, Quart. J. Micr. Sc., 1955, 96, 151.

16. Edwards, G. A., Ruska, H., Souza-Santos, P., and Vallejo-Freire, A., Comparative cytophysiology of striated muscle with special reference to the role of the endoplasmic reticulum, J. Biophysic. and Biochem. Cytol., 1956, 2, No. 4, suppl., 143.

17. Fawcett, D. W., and Revel, J. P., The sarcoplasmic reticulum of a fast-acting fish muscle, J. Biophysic. and Biochem. Cytol., 1961, 10, No. 4, suppl., 89.

18. Fawcett, D. W., and Selby, C. C., Observations on the fine structure of the turtle atrium, J. Biophysic. and Biochem. Cytol., 1958, 4, 63.

19. Heidenhain, M., Plasma und Zelle, Eine allgemeine Anatomie der lebendiger Masse, Zweite Lieferung, Jena, Gustav Fischer, 1911.

20. Hill, A. V., On the time required for diffusion and its relation to processes in muscle, Proc. Roy. Soc. London, Series B., 1948, 135, 446.

21. HrLl, A. V., The abrupt transition from rest to activity in muscle, Proc. Roy. Soc. London, Series B, 1949, 136, 399.

22. Huxley, A. F., Local activation of muscle, Ann. New York Acad. Sc., 1959, 81, 446.

23. Huxley, H. E., Muscle cells in The Cell, (J. Brachet and A. E. Mirsky, editors), New York, Academic Press, Inc., 1960, 4,

24. Huxley, A. F., and Straub, R. W., Local activation and interfibrillar structures in striated muscle, J. Physiol., (London), 1958, 143, 40.

25. Huxley, A. F., and TAYlor, R. E., Function of Krause's membrane, Nature, 1955, 176, 1068. 
26. Huxley, A. F., and TAylor, R. E., Local activation of striated muscle fibers, J. Physiol., $1958,144,426$.

27. Lindner, E., Die submikroskopische Morphologie des Herzmuskels, Z. Zellforsch. u. mikr. Anat.., 1957, 45, 702.

28. Marsh, B. B., Biochim. et Biophysica Acta, 1952, $9,247$.

29. Mauro, A., and Adams, R. W., The structure of the sarcolemma of the frog skeletal muscle fiber, J. Biophysic. and Biochem. Cytol., 1961, 10, No. 4, suppl., 177.

30. Moore, D. H., and Ruska, H., Electron microscope study of mammalian cardiac muscle cells, J. Biophysic. and Biochem. Cytol, 1957, 3, 261.

31. Muscatello, U., Andersson-Cedergren, E., Azzone, G. F., and von der Decken, A., The sarcotubular system of frog skeletal muscle, $J$. Biophysic. and Biochem. Cytol., 1961, 10, No. 4, suppl., 201.

32. Negai, T., Makinose, M., and Hasselbach, W., Der physiologische Erschloffungsfaktor und die Muskelgrana, Biochim. et Biophysica Acta, 1960, 43, 223.

33. Palade, G. E., The endoplasmic reticulum, $f$. Biophysic. and Biochem. Cytol., 2, No. 4, suppl., 85.

34. Parker, C. J., and Gergely, J., The role of calcium in the adenosine triphosphatase activity of myofibrils and in the mechanism of the relaxing factor system of muscle, J. Biol. Chem., 1961, 236, 411.

35. Peachey, L. D., Structure of the longitudinal body muscles of amphioxus, $J$. Biophysic. and Biochem. Cytol., 1961, 10, No. 4, suppl., 159.

36. Peachey, L. D., and Porter, K. R., Intracellular impulse conduction in muscle cells, $S c i$ ence, 1959, 129, 721 .

37. Porter, K. R., Observations on a submicroscopic basophilic component of the cytoplasm, J. Exp. Med., 1953, 97, 727.

38. Porter, K. R., Electron microscopy of basophilic components of cytoplasm, J. Histochem. and Cytochem., 1954, 2, 346.

39. Porter, K. R., The sarcoplasmic reticulum in muscle cells of Amblystoma larvae, J. Biophysic. and Biochem. Cytol., 1956, 2, No. 4, suppl., 163.

40. Porter, K. R., The ground substance: observations from electron microscopy, in The Cell, (J. Brachet and A. E. Mirsky, editors), New York, Academic Press, Inc., 1961, 2, 621.

41. Porter, K. R., and Kallman, F. L., Significance of cell particulates as seen by electron microscopy, Ann. New York Acad. Sc., 1952, 54, 882.

42. Porter, K. R., and Palade, G. E., Studies on the endoplasmic reticulun. III. Its form and distribution in striated muscle cells, J. Biophysic. and Biochem. Cytol., 1957, 3, 269.

43. REGER, J. F., The fine structure of neuromuscular junction and the sarcoplasmic reticulum of extrinsic eye muscles of Fundulus heteroclitus, $J$. Biophysic, and Biochem. Cytol., 1961, 10, No. 4, suppl., 111.

44. Retzius, G., Zur Kenntniss der quergestreifen Muskelfasern, Biol. Untersuch. Jahrb., 1881, 1.

45. Retzius, G., Muskelfibrille und Sarcoplasma, Biol. Untersuch., 1890, N.F., 1, 51.

46. Revel, J. P., Electron microscopic study of the bat cricothyroid muscle, Anat. Rec., 1961, 139, 267 (abstract).

47. Revel, J. P., 1961, personal communication.

48. Robertson, J. D., Some features of the ultrastructure of reptilian skeletal muscle, $J$. Biophysic. and Biochem. Cytol., 1956, 2, 369.

49. Robertson, J. D., The ultrastructure of cell membranes and their derivatives, Biochem. Soc. Symp., 1959, No. 10, 3.

50. Ruska, H., Elektronenmikroskopischer Beitrag zur Histologie des Skelettmuskels. Kleiner Sängetiere, Z. Naturforsch., 1954, 9 J, 358.

51. Ruska, H., Edwards, G. A., and Caesar, R., A concept of intracellular transmission of excitation by means of the endoplasmic reticulum, Experientia, 1958, 14, 117.

52. Simpson, F. O., and Oertelis, S. J., Relationship of the saicoplasmic reticulum to sarcolemma in sheep cardiac muscle, Nature, 1961, 189, 758.

53. Skoglund, C. R., Functional analysis of swimbladder muscles engaged in sound production of the toadfish, J. Biophysic. and Biochem. Cytol., 1961, 10, No. 4, suppl., 187.

54. Sмiтh, D. S., Reticular organization within the striated muscle cell. An historical survey of light microscopic studies, J. Biophysic. and Biochem. Cytol., 1961, 10, No. 4, suppl., 61.

55. SмrтH, D. S., The structure of insect fibrillar flight muscle. A study made with special reference to the membrane systems of the fiber, $J$. Biophysic. and Biochem. Cytol., 1961, 10, No. 4, suppl., 123.

56. SмITH, D. S., The organization of the flight muscle in a dragonfly, Aeshna sp. (Odonata), J. Biophysic. and Biochem. Cytol., 1961, 11, in press.

57. Veratti, E, Recherche sulle fine struttura della fibra muscolare striata. Memorie Ist. Lomb., Cl. di sc., e nat., 1902, 19, 87-133.

58. VERATTI, E., Investigations on the fine structure of the striated muscle fibre, J. Biophysic. and Biochem. Cytol., 1961, 10, No. 4, suppl., 3.

59. Weinstein, H. J., An electron microscope study of cardiac muscle, Exp. Cell Research, 1954, 7, 130. 